\title{
The impact of Group Intelligence software on enquiry-based learning
}

Article

Accepted Version

Proof Version

Tan, Y. L. and Macaulay, L. A. (2011) The impact of Group Intelligence software on enquiry-based learning. The International Journal of Learning, 6 (1). pp. 84-102. ISSN 1447-9494 doi: https://doi.org/10.1504/IJLT.2011.040151 Available at https://centaur.reading.ac.uk/26316/

It is advisable to refer to the publisher's version if you intend to cite from the work. See Guidance on citing.

Published version at: http://www.inderscience.com/search/index.php? action=record\&rec_id $=40151$ \& prevQuery $=\& p s=10 \& \mathrm{~m}=$ or

To link to this article DOI: http://dx.doi.org/10.1504/IJLT.2011.040151

Publisher: Inderscience

All outputs in CentAUR are protected by Intellectual Property Rights law, including copyright law. Copyright and IPR is retained by the creators or other copyright holders. Terms and conditions for use of this material are defined in the End User Agreement.

www.reading.ac.uk/centaur

\section{CentAUR}

Central Archive at the University of Reading 
Reading's research outputs online 


\title{
The impact of Group Intelligence software on enquiry-based learning
}

\section{Yin Leng Tan*}

Department of Business Information Technology and Enterprise, School of Engineering,

University of Greenwich,

Central Avenue, Chatham Maritime,

Kent, ME4 4TB, UK

E-mail: y.tan@gre.ac.uk

*Corresponding author

\author{
Linda A. Macaulay \\ Manchester Business School, \\ University of Manchester, \\ Booth Street East, Manchester M15 6PM, UK \\ E-mail: linda.macualay@manchester.ac.uk
}

\begin{abstract}
Despite the increasing use of groupware technologies in education, there is little evidence of their impact, especially within an enquiry-based learning (EBL) context. In this paper, we examine the use of a commercial standard Group Intelligence software called GroupSystems ${ }^{\circledR T h i n k T a n k . ~ T o ~}$ date, ThinkTank has been adopted mainly in the USA and supports teams in generating ideas, categorising, prioritising, voting and multi-criteria decisionmaking and automatically generates a report at the end of each session. The software was used by students carrying out an EBL project, set by employers, for a full academic year. The criteria for assessing the impact of ThinkTank on student learning were those of creativity, participation, productivity, engagement and understanding. Data was collected throughout the year using a combination of interviews and questionnaires, and written feedback from employers. The overall findings show an increase in levels of productivity and creativity, evidence of a deeper understanding of their work but some variation in attitudes towards participation in the early stages of the project.
\end{abstract}

Keywords: collaborative learning; enquiry-based learning; EBL; technology enhanced learning; Group Intelligence software.

Reference to this paper should be made as follows: Tan, Y.L. and Macaulay, L.A. (xxxx) 'The impact of Group Intelligence software on enquiry-based learning', Int. J. Learning Technology, Vol. X, No. Y, pp.000-000.

Biographical notes: Yin Leng Tan is a Lecturer in Business Software Development in the Department of Business Information Technology and Enterprise at the University of Greenwich, UK. She was a Teaching Fellow associated with the new degree BSc Information Technology Management for Business (ITMB) at the University of Manchester between 2007 and 2008. Her research interests include technology enhanced collaborative learning, innovation and entrepreneurship, and SMEs and service ecosystems. 
Linda A. Macaulay is a Professor of System Design and the Director of the Centre for Service Research at the Manchester Business School, UK. She was the Programme Director associated with the new degree BSc ITMB between 2007 and 2009. Her research focus is on how technical system design can be informed by the needs of users and groups of users.

This paper is a revised and expanded version of a paper entitled 'Enhancing collaborative learning through group intelligence software' presented at the 1st International Conference on Technology Enhanced Learning, Quality of Teaching and Reforming of Education, Athens, 19-21 May 2010.

\section{Introduction}

Groupware and computer-mediated communication are a significant development in higher education where academics strive to respond to employers' ever growing demand for graduates who are effective team players. Video conferencing, blogs, wikis, social networking sites, project management tools and virtual environment learning platforms such as Second Life all play a key role in supporting collaborative learning among student teams (Papamichail et al., 2009).

Enquiry-based learning (EBL) is widely reported in the literature (e.g., Biggs, 1999; Smith and MacGregor, 1992) as an approach that encourages participation, deeper learning and improved motivation, among student teams. Thus, highlighting the importance of providing frameworks such as EBL where students can map out their own learning process and 'learn by doing'.

This paper describes an EBL project where a commercial state-of-the-art Group Intelligence tool 'GroupSystem ${ }^{\circledR}$ ThinkTank' was employed to enhance collaborative learning within student teams. ThinkTank has been successfully employed in commercial environments; however, little attention has been paid to using it in classrooms (Faulkner, 2005). Although ThinkTank has been used in higher education in the USA (Southeastern Louisan University) and Canada (Mohawkk College), within the UK, the University of Manchester was the first to use it in the education setting and in the context of EBL. Thus, this study aims to evaluate the effectiveness of ThinkTank when used in EBL.

The paper is structured as follows: Section 2 gives an overview of the key concepts associated with team-based EBL and groupware supported collaborative learning. Section 3 presents a description of the team project and method used for the EBL project. Section 4 gives the outcomes of the EBL project. An evaluation of the impact of ThinkTank in collaborative learning among student teams in terms of students, tutors and employers' perspective and a summary of the findings are presented in Section 5.

\section{Theoretical framework}

The theoretical framework of the paper is drawn from the literature on collaborative learning and EBL. 'Collaborative learning' refers to a situation where learning involves groups of students working together, "mutually searching for understanding, solutions, or meanings, or creating a product” (Smith and MacGregor, 1992). Findings from Alavi (1994) indicate that collaborative learning supported by groupware can lead to higher 
levels of learning than groups not using groupware. EBL refers to "an array of classroom practices that promote student learning through guided and, increasingly, independent investigation of complex questions and problems, often for which there is no single answer" (Lee et al., 2004).

A review of a number of studies on teamwork, computer-supported collaborative learning, and EBL suggests that five key concepts of participation, creativity, productivity, engagement, and understanding are important (Macaulay et al., 2009; Tan and Macaulay, 2010). The theoretical framework and related literature are shown in Table 1.

Table 1 Theoretical framework of collaborative learning and EBL

\begin{tabular}{ll}
\hline Concepts & Related literature \\
\hline $\begin{array}{l}\text { Participation: level of teamwork, participation } \\
\text { in discussion }\end{array}$ & $\begin{array}{l}\text { Aiken et al. (1995), Guzzo and Dickson } \\
\text { (1996), Karau and Williams (1993), Kahn } \\
\text { and O’Rourke (2005), Nunamaker et al. } \\
\text { (1996) and Manning and Riordan (2000) }\end{array}$ \\
$\begin{array}{l}\text { Productivity: level of achievement, quality of } \\
\text { outcome }\end{array}$ & $\begin{array}{l}\text { Karau and Williams (1993), Nunamaker et al. } \\
\text { (1996) and Manning and Riordan (2000) }\end{array}$ \\
$\begin{array}{l}\text { Creativity: level of contribution of ideas, } \\
\text { novelty }\end{array}$ & $\begin{array}{l}\text { Edelson et al. (1999) and Kahn and O’Rourke } \\
\text { (2005) }\end{array}$ \\
$\begin{array}{l}\text { Engagement: level of motivation, passion for } \\
\text { their work, enthusiasm }\end{array}$ & $\begin{array}{l}\text { Edelson et al. (1999), Karau and Williams } \\
\text { (1993) and Kravitz and Martin (1986) }\end{array}$ \\
$\begin{array}{l}\text { Understanding: level of understanding of the } \\
\text { problem, and application of theory to practice }\end{array}$ & $\begin{array}{l}\text { Cocea and Weibelzahl (2006), Kahn and } \\
\text { O’Rourke (2005) and Lee et al. (2004) }\end{array}$ \\
\hline
\end{tabular}

- Participation

One of the issues with teamwork is that, on average, $20 \%$ of the members do $80 \%$ of the talking (Nunamaker et al., 1996). A number of studies (Aiken et al., 1995; Guzzo and Dickson, 1996; Manning and Riordan, 2000; Nunamaker et al., 1996) show that groupware is able to increase the levels of participation and ensure equal contribution from team members via features of anonymity and parallel information input. As a result of the anonymity provided by computer-mediated collaboration tools, members tend to give more honest opinions on ideas, and are more likely to question ideas or comments if they are not understood (Guzzo and Dickson, 1996; Manning and Riordan, 2000).

- $\quad$ Productivity

One of the main issues with traditional face-to-face meetings is productivity loss. Prior research identified three types of productivity loss; namely social pressure (individual worry about the consequences of giving an idea), social loafing (one or more members not contributing owing to, for example, a lack of interest or motivation) and production blocking (one member is contributing to the team while others are listening and not able to contribute until he or she is finished) (Carroll, 2003; Karau and Williams, 1993). Research shows that productivity can be enhanced by groupware via features of parallel input (Manning and Riordan, 2000; Nunamaker et al., 1996). 


\section{- Creativity}

One of the key advantages of EBL is that learners are given the freedom to create their own ideas/knowledge (Edelson et al., 1999; Kahn and O’Rourke, 2005). By applying a 'learning by doing' approach, learners will be required to think about the research problems and formulate their own solutions; this could leave learners in a much better position to create knowledge/ideas, thus, relying much more on their own creativity. Coopman (2001) states that the level of creativity could be enhanced when people work together on a project.

- Engagement

“The learners' motivation has an impact on the quality of learning” (Cocea and Weibelzahl, 2006). Keeping students engaged has always been a major issue for higher education. Although working in a group can sometimes increase the level of individual motivation, at other times group work can also undermine it (Carroll, 2003). Although many concepts are likely to affect a team's motivation, Coch and French (1948) claimed that the group will apply more effort to the task if the members are able to set their own goals rather than the goals being imposed by tutors. It is suggested that EBL could enhance student learning and motivation (Biggs, 1999; Lee et al., 2004).

- Understanding

Kahn and O’Rourke (2005) claimed that traditional 'passive' approaches only promote 'surface learning' while EBL allows students to make their own connection between different pieces of information which triggers deeper understanding. An advantage of EBL over traditional teaching methods is that EBL aims to guide students into a deeper level of understanding by encouraging a practical approach to problem solving (Cocea and Weibelzahl, 2006; Kahn and O’Rourke, 2005; Lee et al., 2004). This allows students to gain understanding of theory through practice rather than just understanding the theory through a third party (e.g., the tutors).

In summary the literature suggests that collaborative EBL should enhance the level of participation, improve productivity and creativity, result in more engagement and a deeper understanding among students. The five key concepts of participation, productivity, creativity, engagement and understanding are used throughout this paper. Section 3 describes the main elements of the EBL project and the role of ThinkTank within that. Section 4 uses the five key concepts as a basis for examining student learning and the impact of ThinkTank on the project.

\section{Method}

This section describes the method used for the EBL project, including the task, team arrangement, structure of the project, the involvement of the tutors and business mentors, and teamwork supported by the Group Intelligence tool and Group Intelligence Lab. The project, as part of the CEEBL project (Macaulay et al., 2009), was undertaken by first year students on the BSc Information Technology Management for Business (ITMB) degree. 


\subsection{The task and team arrangement}

The task set for the EBL project was to examine a university website from the point of view of a business seeking advice, consultancy or access to the results from research conducted by university staff; to identify problems and to redesign the site to solve those problems. The 45 undergraduate students were divided into eight teams of five or six. Each team had the freedom to arrive at their own solution to the problem by following the stages: problem definition; user requirements; scope of the solution; high-level design; detailed design; implementation; testing and evaluation; and demonstration and documentation.

The EBL Integrative Team Project lasted one year, starting in September and ending at the beginning of May. The timeline in Figure 1 shows the key stages of the project and the key points of integration of learning from co-requisite modules: Human Computer Interactions, Business Application Design and Development, Database Design and Development, and Guru Lectures and Professional Development.

Figure 1 The EBL project timeline and contribution of other taught modules (see online version for colours)

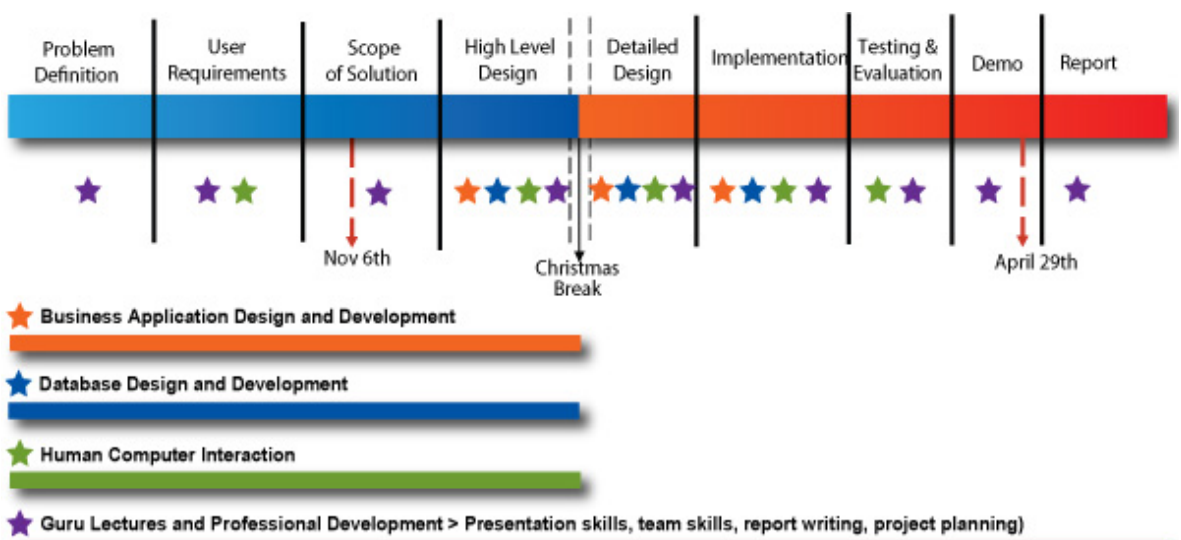

\subsection{Structure of the team project}

The structure of the EBL project was a one-hour lecture and a two-hour tutorial session each week throughout the whole academic year, with an additional four hours of technical support in semester two.

The one-hour lecture provided students with information about the team project; prepared them for the week-by-week tasks; introduced theories associated with group and team working skills and group facilitation skills; and introduced techniques for information gathering, interviewing end users and system evaluation. The aim of the tutorial was to enable and encourage students to adopt an EBL approach ('learning by doing'). Students met with tutors to discuss their ideas and used GroupSystems ${ }^{\circledR}$ ThinkTank ${ }^{1}$ in the first semester for problem definition and requirements gathering; and again in second semester for decision-making. 


\subsection{Team work supported by Group Intelligence software and Group Intelligence Lab}

GroupSystems ${ }^{\circledR}$ ThinkTank was used to support the teamwork among the student teams. Referring to seminal work of Jay Nunamaker in the 1980s, for example, Nunamaker (1989) and GroupSystems (2009) provide further context:

"Dr. Jay Nunamaker (Univ. of Arizona) and our co-founders postulated that the negative impact of peer dynamics and a lack of structure in collaboration dramatically limit the quality and quantity of the output of people working on a common problem.

They went further to research, test, develop, and encode in software a series of methodologies and systems designed specifically to maximize the outcomes of such groups.

In 1989, after tremendous success in both the lab and in groundbreaking joint projects with IBM and the US Navy, GroupSystems was launched as a commercial venture and now supports the largest global customer base in Group Intelligence Technology within Government, Military, Education and Corporate segments."

The latest version, GroupSystems ${ }^{\circledR}$ ThinkTank is an internet enabled real-time group collaboration software which enables group brainstorming, categorisation, prioritisation, voting, consensus building, strategic alignment, multi criteria decision-making, and project-planning tool.

Figure 2 A brainstorm session of 'problem definition' in ThinkTank (see online version for colours)

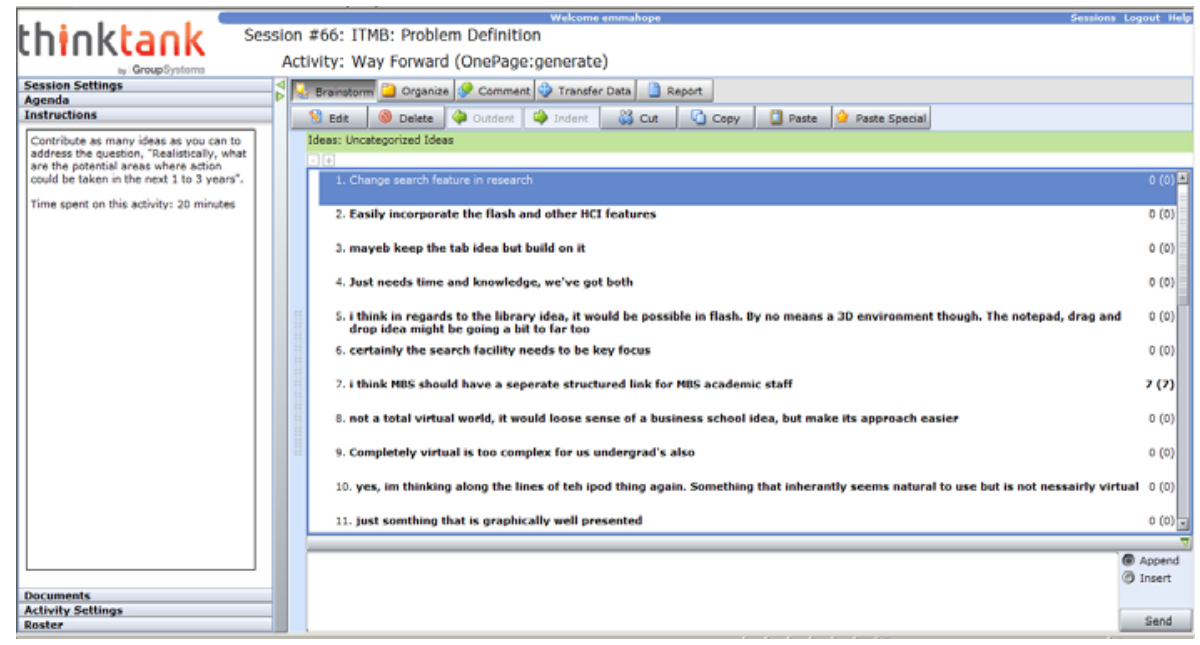

A ThinkTank session assumes a facilitator whose role is to set the agenda; create the group session and control the agenda while the session is in progress. In the case of team project reported in this paper, the facilitator was one of the tutors. Each group is given different group session ID enabling a number of sessions to be run simultaneously while maintaining privacy of information from one group to the next. Each individual can only see the inputs from his or her own group. Figure 2 shows a typical ThinkTank free 
brainstorming session. Individuals input their ideas and these can be viewed by everyone in their group. Individuals can also comment on each others ideas.

Besides free brainstorm, ThinkTank also allows students categorised their ideas according to certain categories. The categories are usually pre-defined by session facilitator during the session or agenda design. For example, in one of the ThinkTank sessions, the student groups were asked to:

1 Identify a list of tasks for their selected target users.

2 Classify the list of tasks that they generated into 'primary', 'secondary' and 'tertiary' tasks. These were carried by simply drag and drop the idea to the specified 'bucket' of category.

3 Select tasks they would like to develop further, in other words, building consensus of the tasks that the team would like to carry forward, this was carried out by each member performing a 'rank order vote'.

The voting results can be displayed as a table or as chart as shown in Figure 3.

Figure 3 A ThinkTank group support system rank order chart (see online version for colours)

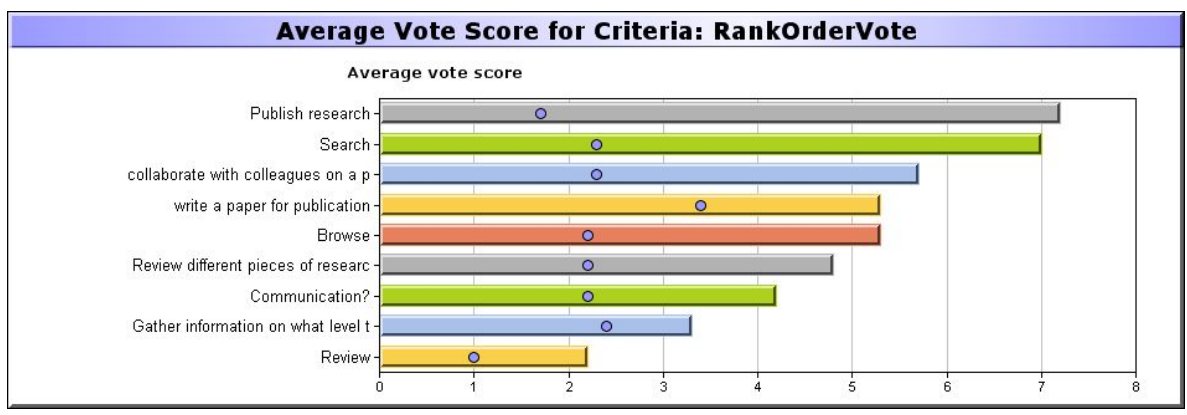

Lackney (2005) underlines that configuring a learning space to provide for group learning is essential to facilitating social learning and stimulation. A Group Intelligence Lab was also set up to support both face-to-face and computer-mediated communication.

The layout of the lab has been specially designed where computer desks are arranged in group of six with students sitting around the table facing each other. Each computer desk is designed to enable an LCD monitor concealed within the desk, one per student. Students can work face-to-face in an unobstructed line-of-sight with the LCD screen down (i.e., positions the LCD monitor below the horizon line, with a clear work surface) or can work online with screens raised. Thus, allowing interchange between verbal communication and computer-mediated communication.

Moore (1989) states that 'learner-instructor' interaction is important in student learning since the instructor will be "crucial in providing authoritative, stimulating, motivating and interesting content, as well as supporting, encouraging, and verifying the learner's response to knowledge application”. In the context of the EBL project, a ThinkTank session was set up for each team. Once the session has been set up, the students will interact with each other to come out with the solution. The facilitator who set up the sessions for the teams in ThinkTank, thus, acts as the instructor controlling the 
overall process of the discussion, providing encouragement and support to enable the students to take responsibility for what and how they learn.

A typical ThinkTank session contains the following activities: brainstorming and commenting ideas (10-15 minutes), categorising ideas (10-15 minutes), prioritising ideas (10-15 minutes) and voting and generating reports (10-15 minutes). For example, to get the student teams to 'identify the problems of an existing university website', a session called 'problem definition' was set up to help brainstorm ideas about the users of the system and to what types of business knowledge they might want access. Figure 2 shows one of the brainstorm activities using GroupSytems ${ }^{\circledR}$ ThinkTank. At the end of the one-hour ThinkTank session, a group report was generated in Microsoft ${ }^{\circledR}$ Word or XML format for students to download.

\subsection{Academic tutors and employer mentors}

For EBL to be effective, apart from getting students to complete a task, it is important that the process is supportive (Edelson et al., 1999; Kahn and O’Rourke, 2005). Each team was also assigned an academic tutor and a business mentor. The role of the tutors was to provide support to the student teams regarding their project. Tutors also acted as assessors for the group presentations and provided individual assessment of each team member. The student teams met with their tutors on a weekly basis for an hour at the tutorial session. The business mentors provided extra-curricular support for the teams. Student teams met with their mentors twice a year. The meeting arrangements with the mentors were organised by the student teams. The business mentors in the academic year of 2007-2008 were from Deloitte, BBC, Procter \& Gamble (P\&G) and Unilever.

The outcomes of the EBL project as a result of the use of ThinkTank are discussed below.

\section{Outcomes}

As a result of the EBL approach and teamwork supported by ThinkTank, six weeks into the team project the student teams were able to produce their interim results (problems, visions, target users and solutions) with ideas ranging from virtual library to social networking websites. Each of the eight student teams produced a different solution to the problem. At the early stage of envisioning, their ideas included: improved search engines; virtual world demonstrations; use of metaphors for guiding users through the site and improvement of the user interface design to enable hidden data to appear at the top level. At later stages students had to propose a number of alternative solutions and assess their feasibility against a number of criteria. Each team, thus, chose what they would design and implement.

The outcomes were presented at the first ITMB employers' event which was attended by members of ITMB Supporters Club. The ITMB Supporters Club is a group of employers who support the ITMB programme and meet twice a year to network with students and staff to exchange the latest news and identify future opportunities for interaction. 
The first ITMB employers' event was held on the 6th November 2007, the employers attending the event included IBM, Deloitte, Logica CMG, Royal Bank of Scotland (RBS), RM, P\&G, E-Skills UK, BT, SAP, Unilever, edge IPK, BBC and Accenture. At the event, the student teams presented their ideas and answered questions asked by employers. The event received positive feedback from both the students and the employers.

The semester two ITMB employers' event was held on the 29th April 2008, employers attending included IBM, Accenture, LogicaCMG, Unilever, Deloitte, Network Rail, P\&G, E-Skills UK, Informed Solutions, RM, BT and RBS. At this event, the student teams were required to produce posters and demonstrate their final software prototype to employers. A poster stand was provided to each student team where they displayed their posters. A laptop with internet connection was also set up for each team where a live demo of their prototype to the employers can be taken place; questions were then asked by the employers to the student teams at the event. The event was a half-day event, started from 12:30 PM and finished at 5:30 PM.

An award of the Unilever Prize for best group poster and demonstration was presented at the end of the event. The judging of the group posters/demonstrations was carried out by a panel of employers based on the five concepts as outlined in Section 2; creativity (idea originality and novelty), level of participation, engagement of the team members, productivity (completeness of the product) and level of understanding (by applying theory to practice).

Next section presents the evaluation of the impact of ThinkTank on EBL.

\section{Evaluation of Group Intelligence software in collaborative learning}

The evaluation of the effectiveness of Group Intelligence software in collaborative learning was based on feedback gathered from students and employers. Tutors' opinions on the EBL project of using the tool are also outlined.

\subsection{Students' feedback}

Questionnaires were distributed to students requesting feedback on their perception of the level of participation, creativity, productivity, engagement and understanding. The questions asked and results of the responses are shown in Appendix 1. In addition to the questionnaires, five in-depth interviews were conducted (interview questions are shown in Appendix 2).The criteria for choosing the interview were based on volunteering. Each student team was asked to put forward one volunteer who would represent their team opinions. An analysis of the five interviews and 35 questionnaire responses is presented as below.

\subsubsection{Participation}

As presented earlier, it is suggested that groupware could increase participation among student teams. Findings from the interviews (iQ4 and iQ6) revealed that most interviewees felt that they were able to contribute more freely using ThinkTank when compared to traditional face-to-face meetings. Results from the questionnaire (Q3) correlate with the findings from the interviews, with $93 \%$ of the students (rated 6 or 
above) clearly indicating that ThinkTank allowed them to participate more freely. As stated by one of the interviewees, "ThinkTank being anonymous... don't have to be cautious with others because they don't know who it [the input/idea] came from".

According to Nunamaker (1997), Guzzo and Dickson (1996) and Manning and Riordan (2000), the increase in participation is mainly due to two key features in the design of groupware; the feature of anonymity and parallel input. The results of the interviews (iQ4, iQ6 and iQ12) showed that students overall agreed that being anonymous and having parallel input increases participation. Interestingly, students also expressed (iQ13) that they would have liked the level of their input to be recognised. The questionnaire results (Q4) also revealed that some $50 \%$ (17 rated 5 or below) indicated that they would have liked the level of their input to be recognised when using computermediated collaborative tools.

\subsubsection{Productivity}

The three productivity losses in traditional meetings as underlined by Carroll (2003) are social loafing, social pressure and production blocking. In terms of social pressure, the interviews (iQ4, iQ5 and iQ6) suggested that students feel that anonymity of ThinkTank does reduce social pressure and inputs were more honest. The questionnaire results (Q15) also suggested that students felt tasks were more important to them in ThinkTank than in traditional meetings, with 25 rated 6 or above, this could suggest that they exerted more effort in the tasks when using ThinkTank.

In terms of production blocking, the interviews results (iQ6, iQ7 and iQ8) showed that students recognised that the feature of parallel input in ThinkTank increased their productivity. According to the interviewees, the reason behind this was because "all of them contributed rather than in a traditional meeting where half of them don't say anything". Another stated that "the structure of ThinkTank allowed us to give ideas first instead of drilling on a few ideas".

As for the questionnaire (Q7), although the standard deviation was relative high, over $60 \%$ (i.e., 21 rated 6 or above) did agree ThinkTank allows them to create more ideas.

\subsubsection{Creativity}

In a traditional meeting, very often ideas would be generated by one or two members of the group. The results from the interviews (iQ8 and iQ12) showed that students were less likely to be influenced by fellow team members in ThinkTank; therefore, ideas can be freely expressed. However, students have a tendency to read other members' ideas during a brainstorm process. These could have lowered the diversity of ideas as their inputs could potentially be affected by the other group members' ideas, and time constraints for each activity in ThinkTank. The reason behind this, according to the interviewees, was because they did not want to repeat any ideas that have already been said, and others claimed that they did not want a 'massive load to read at the end'.

The results of the questionnaires (Q5) also showed that $66 \%$ (23 rated 6 or above) felt that they were able to fully express their ideas. Interestingly, the findings of questionnaires (Q6) showed that some 35\% of them (12 rated 4 or below) felt that they could not always fully understand the ideas expressed by their team members. 


\subsubsection{Engagement}

According to Karau and Williams (1993), individuals would be more motivated to work if:

1 they believe that their input to the task is unique

2 other members perform badly; therefore, he/she needs to put in more effort for success

3 he/she sees the group as high value, i.e., he/she likes the group.

The findings from the interviews (iQ3) showed that students generally felt that they played an important role within their group. One interviewee stated that, "it is a combined effort from every member of the group although I do have an all round ability". The results of questionnaires (Q2) also revealed that $88 \%$ (31 rated 6 or above) of the students generally felt that they were able to contribute individually to their team.

When comparing the amount of effort other members inputted to the tasks in ThinkTank (Q14), the results of the questionnaires revealed that students clearly felt that other members' of the team exerted the same amount of effort as themselves, i.e., $63 \%$.

Findings indicate lower motivation (Q9), with only 11 rated 6 or above, in teamwork when ThinkTank is used; however, students felt the task (Q15) was more important to them when using ThinkTank compared to a traditional face-to-face meeting.

\subsubsection{Understanding}

The interview results (iQ15 and iQ17) revealed that students agreed that they were able to directly convert the information/knowledge they gathered/learned into practice. Interviewees indicated the report feature of ThinkTank was the main reason for this. According to one interviewee, "it saved time and it ensured that all the information was reported". Apart from this he also felt that by having the same report at the end of the sessions, everybody was "more on the same wavelength".

The process of carrying out a ThinkTank session also allowed students to trigger a deeper understanding of their project. By allowing 'teaming', which is a process of exploring ideas, ThinkTank enables students the chance to understand the problem and eventually devise a solution to the problem.

\subsection{Employers' feedback}

The employer feedback of the EBL project was carried out at the ITMB employers' event which held on 29th April 2008 when student groups demonstrated their solutions. A feedback form (see Appendix 3) based on the five concepts of participation, productivity, creativity, engagement and understanding for each team was completed by the employers. Nine employers from IBM, Accenture, E-Skills UK, Deloitte, Unilever, BT and Informed Solutions participated in the project evaluation. A total of 51 copies of the evaluation forms were received. Figure 4 shows the employers' feedback of the student teams based on their level of participation, productivity, creativity, engagement and understanding. 
Figure 4 Employer evaluation of the student teams based on the five concepts: participation, productivity, creativity, engagement and understanding (see online version for colours)

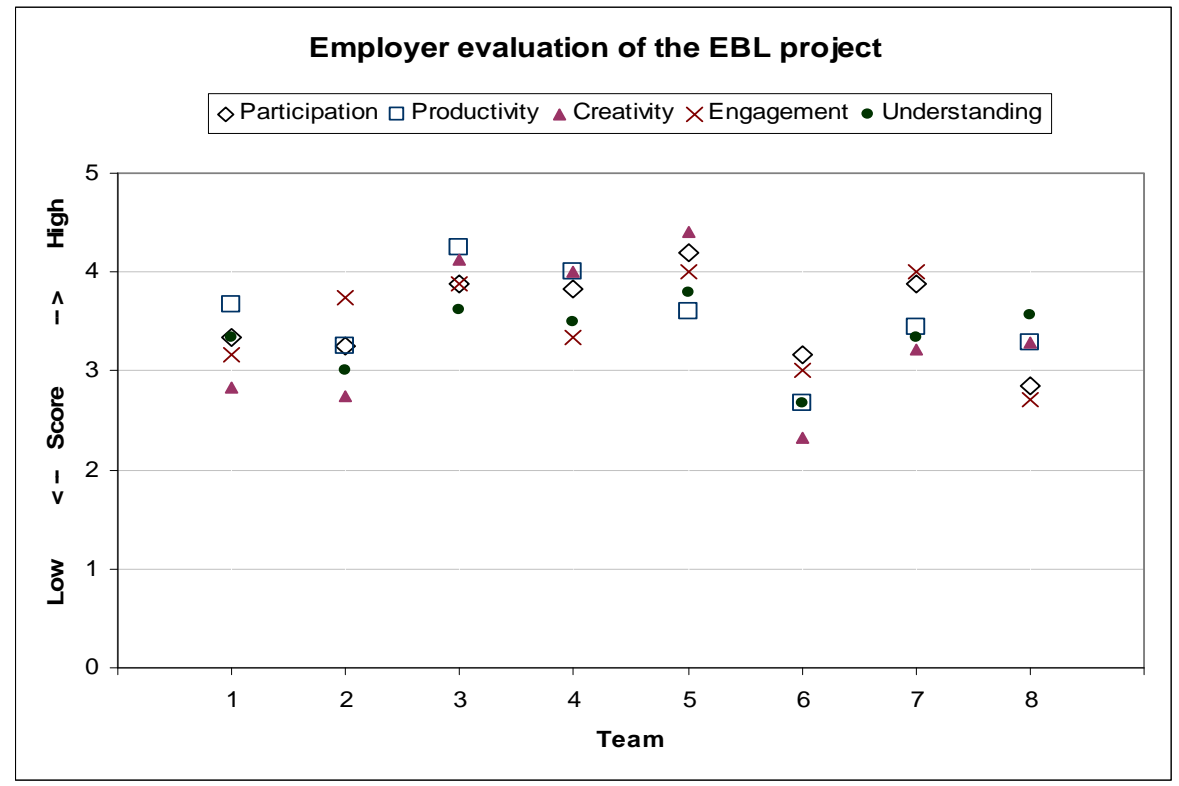

The results show that in terms of level of teamwork and participation in discussion, four out of the eight student teams were considered as 'average', three of them were considered 'very good', and one of them was regarded as 'highly participative'. In terms of productivity, i.e., level of achievement and quality of the solutions, six out of the eight teams were regarded as 'very good' by the employers.

In terms of creativity, i.e., level of contribution of own ideas and novelty, one of them was regarded as 'highly creative', and four of them were regarded as 'very creative' by the employers.

As for the engagement, i.e., level of motivation, passion for their work and enthusiasm, five of the teams were considered to have a 'very good' level of engagement by the employers. The rest of the three teams were considered 'good'.

In terms of level of understanding of the problem, and application of theory to practice, the results showed that five of the teams were regarded as having a 'deep understanding' of the problem. Two of them were regarded as 'average' and one of them were considered to have a 'superficial understanding' of the problem.

\subsection{Tutors' feedback}

This section presents the tutors' opinions of using the tool in the EBL project.

The tutors' felt that ThinkTank enhanced the EBL project in a number of important ways. The brainstorming sessions early in the project required each student to contribute via ThinkTank. Contributions were anonymous and helped some students overcome the initial concerns about participating within their newly formed team. Students commented on each other's ideas and the online discussion was followed by off-line discussion, thus, 
encouraging participation in group discussion from the outset. Nevertheless, some students expressed a desire to have anonymity removed, and for their contribution to be recognised. ThinkTank would support this feature, and in doing so, would enable monitoring students' participation in a similar way to that described in Juan et al. (2009).

Each team session including all brainstorm ideas and comments were captured in the ThinkTank database and at the end of the session a report was automatically generated. This contributed considerably to the productivity of the student teams and enabled them to spend time improving the quality of their reports rather than just capturing the basic outcome. More students contributed ideas, and more discussion of options took place during the ThinkTank prioritisation session leading in turn to the identification of new or new combinations of ideas and ultimately to students being more creative. The level of debate increased and students certainly appeared more passionate than usual about the decisions made by their team, in particular, wanting to find out how their proposed solution would compare with that of their competitors, i.e., the other teams. Proposed solutions had to be converted into actual software-based solutions; hence, a deep and full understanding of their proposal was required.

Besides the advantages of increased levels of productivity, engagement, participation and understanding by the students, the other two main advantages of using ThinkTank are by utilising the state-of-the-art Group Intelligence technology, the tutors would be able to facilitate/guide the student group activities in a more structured way when compared to traditional methods of group facilitation.

\subsection{Summary of findings}

This section draws together the findings from the various evaluations conducted in an attempt to assess the impact of ThinkTank on collaborative EBL. Each of the five key elements of EBL are examined in turn:

- Did ThinkTank enhance the level of student participation?

The findings revealed that ThinkTank did enhance the level of student participation through the features of anonymous and parallel input. The tutors felt that the anonymous feature on ThinkTank did have certain impact on assisting some students overcome the initial concerns about participating within their newly formed team.

- $\quad$ Did ThinkTank improve the productivity of student teams?

The results showed that students generally felt that the tasks were more important to them in ThinkTank than traditional face-to-face meetings, ThinkTank also allowed them to generate more ideas as a result of parallel input. The ThinkTank's report feature also contributed considerably to the productivity of the students teams.

- Did ThinkTank improve the creativity in student project work?

In ThinkTank, ideas can be freely expressed, thus, enhancing creativity. More ideas and more discussion of options took place during the ThinkTank prioritisation session leading in turn to the identification of new or new combinations of ideas and ultimately to students being more creative. 
- Did ThinkTank result in a higher level of student engagement?

The findings revealed that students generally felt that they played an important role within their team and were able to contribute individually to their team.

- Did ThinkTank facilitate a deeper understanding of the EBL project among students?

The findings showed that students were able to directly convert the knowledge they learned into practice, the process of carrying out a ThinkTank session also allowed students to trigger a deeper understanding of their project, as their proposed solutions were successfully converted into actual applications.

\section{Conclusions}

The study was conducted on the first year students of BSc ITMB degree; the students were from a mixed A-level background, e.g., economics, arts, technology, and business studies, prior knowledge of Information Technology or familiarity of IT is not required for enrolling the programme. Nevertheless, the findings may not be generalisable to students in other similar or different contexts. Further research is needed to complete our understanding on this subject in other similar or different settings.

Despite these limitations, the Group Intelligence software enhanced collaborative learning in a number of important ways. The anonymous and parallel input, as well as the report feature of ThinkTank contributed considerably to the participation, productivity, creativity. The process of prioritisation which lead to further discussion/debate of their ideas for proposed solution have an impact on students' creativity and also their level of engagement. In addition, the process of carrying out a ThinkTank session also facilitates a deeper understanding of project among the students.

On all the measures of collaborative EBL: participation; productivity; creativity; engagement; and understanding, the employers scored all eight groups above average compared to student groups they have seen at this university and others (see Figure 4) and although it is difficult to prove in any definite way, faculty staff, employers and students felt that the use of Group Intelligence software played a significant role.

\section{References}

Aiken, M., Govindarajulu, C.D. and Horgan, D. (1995) 'Using a group decision support system for school-based decision making’, Education, Vol. 115, No. 3, pp.420-425.

Alavi, M. (1994) 'Computer-mediated collaborative learning: an empirical evaluation', MIS Quarterly, June, Vol. 18, pp.159-174.

Biggs, J. (1999) 'What the student does: teaching for enhanced learning', Higher Education Research \& Development, Vol. 18, No. 1, pp.57-72.

Carroll, J. (2003) HCI Models, Theories, and Frameworks, Morgan Kaufmann, Elsevier Science, USA.

Cocea, M. and Weibelzahl, S. (2006) 'Can log files analysis estimate learners' level of motivation?', in 14th Workshop on Adaptivity and User Modeling in Interactive Systems, Hildesheim, 9-11 October.

Coch, L. and French, J. (1948) ‘Overcoming resistance to change’, Human Relations, Vol. 1, No. 4, pp.512-532. 
Coopman, S. (2001) Small Group Communications, The McGraw-Hill Companies, available at http://www.mhhe.com/socscience/comm/group/index.html (accessed on 17 February 2009).

Edelson, D.C., Gordin, D.N. and Pea, R.D. (1999) 'Addressing the challenges of inquiry-based learning through technology and curriculum design', The Journal of Learning Science, Vol. 8, Nos. 3-4, pp.391-450.

Faulkner, R. (2005) 'Wired class lets everyone talk at once', The Hamilton Spectator, available at http://groupsystems.files.wordpress.com/2007/09/mohawk-college-class-participation.pdf.

GroupSystems (2009) available at http://www.groupsystems.com/about_us/ (accessed on 20 June 2010).

Guzzo, R. and Dickson, M.W. (1996) 'Teams in organizations: recent research on performance and effectiveness', Annual Review of Psychology, Vol. 47, pp.307-338.

Juan, A.A., Daradoumis, T., Faulin, J. and Xhafa, F. (2009) 'SAMOS: a model for monitoring students' and groups' activities in collaborative, e-learning', International Journal of Learning Technology, Vol. 4, Nos. 1/2, pp.53-72.

Kahn, P. and O’Rourke, K. (2005) 'Understanding enquiry-based learning (EBL)', in Barrett, T., Mac Labhrainn, I. and Fallon, H. (Eds.): Handbook of Enquiry \& Problem Based Learning Galway, pp.1-12, CELT, available at http://www.nuigalway.ie/celt/pblbook/.

Karau, S.J. and Williams, K.D. (1993) 'Social loafing: a meta-analytic review and theoretical integration', Journal of Personality and Social Psychology, Vol. 65, pp.681-706.

Kravitz, D. and Martin, B. (1986) 'Ringelmann rediscovered: the original article', Journal of Personality and Social Psychology, Vol. 50, pp.936-941.

Lackney, J.A. (2005) 'New approaches for school design', in F.W. English (Ed.): The SAGE Handbook of Educational Administration.

Lee, V.S., Greene, D.B., Odom, F., Schechter, E. and Slatta, R.W. (2004) 'What is inquiry-guided learning?', in Virginia, S.L. (Ed.): Teaching and Learning Through Inquiry: A Guidebook for Institutions and Instructors Virginia, Stylus Publishing, Sterling, USA.

Macaulay, L.A., Tan, Y.L. and Chow, R. (2009) 'Group Intelligence, Creativity and Learning. Centre for Excellence in Enquiry-based learning (CEEBL)', The University of Manchester, UK, pp.21-32, available at http://www.campus.manchester.ac.uk/ceebl/projects/casestudies/ 57.pdf.

Manning, L.M. and Riordan, C.A. (2000) 'Using groupware software to support collaborative learning in economics', Journal of Economic Education, Summer, pp.244-252.

Moore, M.C. (1989) 'Three types of interaction', The American Journal of Distance Education, Vol. 3, No. 2, available at http://www.ajde.com/Contents/vol3_2.htm\#editorial (last accessed on 15 February 2009).

Nunamaker, J. (1989) 'Experience with and future challenges in GDSS (group decision support systems): preface', Decision Support Systems, Vol. 5, No. 2, pp.115-118.

Nunamaker, J., Briggs, R., Mittleman, D., Vogel, D. and Balthazard, P. (1996) 'Lessons from a dozen years of group support systems research: a discussion of lab and field findings', Journal of Management Information Systems, Vol. 13, No. 3, pp.163-207.

Nunamaker, J.F. (1997) 'Future research in group support systems: needs, some questions and possible directions', International Journal of Computer Studies, Vol. 47, pp.357-385.

Papamichail, K., Alrayes, A. and Macaulay, L.A. (2009) 'Exploring the potential of virtual worlds for enquiry-based learning', Lecture Notes in Computer Science, Vol. 5736, pp.376-385, ISBN978-3-642-04753-4.

Smith, B.L. and MacGregor, J.T. (1992) What Is Collaborative Learning?, Washington Center for Improving the Quality of Undergraduate Education.

Tan, Y.L. and Macaulay, L.A. (2010) 'Enhancing collaborative learning through group intelligence software', Communications in Computer and Information Science, Springer, Heidelberg, ISBN 978-3-642-16317-3, Vol. 111, pp.453-459. 


\section{Notes}

1 ThinkTank is the trademark of GroupSystems. See http://www.groupsystems.com.

\section{Appendix 1}

\section{Student evaluation questionnaire}

Q1 I enjoyed working with the individuals in my group.

$\begin{array}{lllllllllllll}\text { Disagree } & 1 & 2 & 3 & 4 & 5 & 6 & 7 & 8 & 9 & 10 & \text { Agree }\end{array}$

Q2 I was able to make unique contribution to my team.

$\begin{array}{llllllllllll}\text { Disagree } & 1 & 2 & 3 & 4 & 5 & 6 & 7 & 8 & 9 & 10 & \text { Agree }\end{array}$

Q3 I did not think about other people's feelings when I made a contribution.

$\begin{array}{llllllllllll}\text { Disagree } & 1 & 2 & 3 & 4 & 5 & 6 & 7 & 8 & 9 & 10 & \text { Agree }\end{array}$

Q4 I would have preferred if ThinkTank was not anonymous.

$\begin{array}{llllllllllll}\text { Disagree } & 1 & 2 & 3 & 4 & 5 & 6 & 7 & 8 & 9 & 10 & \text { Agree }\end{array}$

Q5 I was able to fully express my ideas through typing in ThinkTank.

$\begin{array}{llllllllllll}\text { Disagree } & 1 & 2 & 3 & 4 & 5 & 6 & 7 & 8 & 9 & 10 & \text { Agree }\end{array}$

Q6 I understood other member's contributions in ThinkTank.

$\begin{array}{llllllllllll}\text { Disagree } & 1 & 2 & 3 & 4 & 5 & 6 & 7 & 8 & 9 & 10 & \text { Agree }\end{array}$

Q7 The team was able to produce more ideas in ThinkTank than in a traditional meeting.

$\begin{array}{llllllllllll}\text { Disagree } & 1 & 2 & 3 & 4 & 5 & 6 & 7 & 8 & 9 & 10 & \text { Agree }\end{array}$

Q8 There was enough time for me to complete the tasks I was given.

$\begin{array}{llllllllllll}\text { Disagree } & 1 & 2 & 3 & 4 & 5 & 6 & 7 & 8 & 9 & 10 & \text { Agree }\end{array}$

Q9 I felt that I was more motivated in ThinkTank compared to traditional meetings.

$\begin{array}{llllllllllll}\text { Disagree } & 1 & 2 & 3 & 4 & 5 & 6 & 7 & 8 & 9 & 10 & \text { Agree }\end{array}$

Q10 If you were to carry out the same tasks in a traditional meeting, how important would it be for you to reach your goal?

$\begin{array}{llllllllllll}\text { Not } & 1 & 2 & 3 & 4 & 5 & 6 & 7 & 8 & 9 & 10 & \text { Vital }\end{array}$

Q11 I felt that I applied all my efforts to the tasks in ThinkTank.

$\begin{array}{llllllllllll}\text { Disagree } & 1 & 2 & 3 & 4 & 5 & 6 & 7 & 8 & 9 & 10 & \text { Agree }\end{array}$

Q12 How much effort did you feel your other team members exerted on those tasks?

$\begin{array}{llllllllllll}\text { None } & 1 & 2 & 3 & 4 & 5 & 6 & 7 & 8 & 9 & 10 & \text { All }\end{array}$ 
The impact of Group Intelligence software on enquiry-based learning

Q13 Did you feel that you worked harder than other members in your group?

$\begin{array}{llllllllllll}\text { No } & 1 & 2 & 3 & 4 & 5 & 6 & 7 & 8 & 9 & 10 & \text { Yes }\end{array}$

Q14 Did you feel that other members put in as much effort as you?

$\begin{array}{llllllllllll}\text { No } & 1 & 2 & 3 & 4 & 5 & 6 & 7 & 8 & 9 & 10 & \text { Yes }\end{array}$

Q15 How important was it for you to achieve the tasks in ThinkTank?

$\begin{array}{llllllllllll}\text { Not } & 1 & 2 & 3 & 4 & 5 & 6 & 7 & 8 & 9 & 10 & \text { Vital }\end{array}$

Questionnaire results: $(\mathrm{N}=35)$

\begin{tabular}{lccc}
\hline Question no. & Mean & Mode & Standard deviation (SD) \\
\hline 1 & 6.5 & 7 & 2.92 \\
2 & 7.3 & 8 & 2.01 \\
3 & 7.9 & 10 & 1.75 \\
4 & 6.1 & 5 & 2.71 \\
5 & 6.5 & 7.5 & 1.97 \\
6 & 5.8 & 9 & 2.46 \\
7 & 6.1 & 8 & 2.86 \\
8 & 6.1 & 8 & 2.58 \\
9 & 4.3 & 1.5 & 2.94 \\
10 & 6.1 & 6 & 2.07 \\
11 & 5.1 & 6 & 1.86 \\
12 & 8.9 & 7 & 1.99 \\
13 & 6.1 & 7 & 2.57 \\
14 & 6.5 & 10 & 2.69 \\
15 & 6.8 & 7.7 & 2.14 \\
\hline
\end{tabular}

\section{Appendix 2}

\section{Student interviews questions}

iQ1 Do you like working with your group?

iQ2 Do you feel that you have gotten closer to your team members through ThinkTank? If YES how do you think that happened?

iQ3 Do you think you are an important member of your group?

iQ4 When brainstorming, did you think about what others might feel about your idea before making a contribution?

iQ5 Did you only contribute the best of your ideas or would rather brainstorm anything which you think could be useful? 
iQ6 Did you feel that you were able to comment on other members' ideas more freely in ThinkTank comparing to a traditional meeting?

iQ7 Did you feel that your team was able to produce more ideas when you are using ThinkTank compared to traditional meeting?

iQ8 When taking part in a brainstorm, did you prefer to read what other team members have already written? Or would you rather read them all at the end?

iQ9 Did you feel that you were able to fully express your opinions using ThinkTank? If not, why?

iQ10 Did you always understand the ideas that were inputted by your team mates? If not, do you always make sure that the idea was understood? Or do you just ignore it?

iQ11 How often do your ideas get put into practice? Do you feel that the outcome would have been different in a traditional meeting since you able to express yourself better?

iQ12 How much do you feel that you were able to influence the team via ThinkThank?

iQ13 How do you feel about the feature of anonymity in ThinkTank?

iQ14 Did you think your team was overall motivated through the use of ThinkTank?

iQ15 Did you feel that ThinkTank improved your understanding of what you have learnt from other modules?

iQ16 Did you prefer a ThinkTank session than a traditional meeting?

iQ17 Did you feel that the knowledge you gained from the sessions can be put into immediate practice?

\section{Appendix 3}

\section{Employer evaluation form}

- Participation - level of team work, participation in discussion

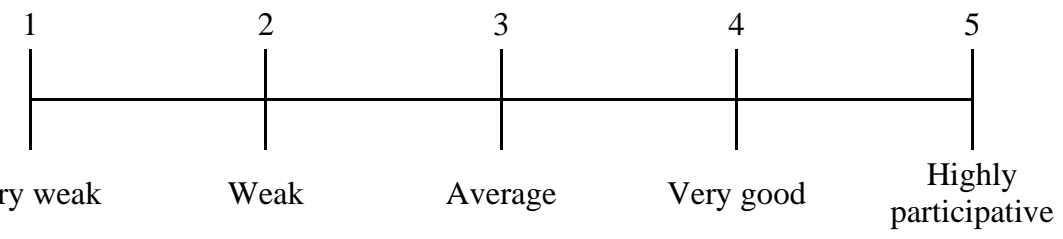

- Productivity - level of achievement, quality of outcomes

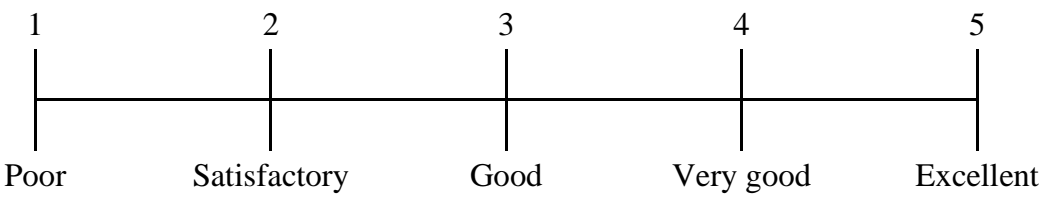


- Creativity - level of contribution of own ideas, novelty

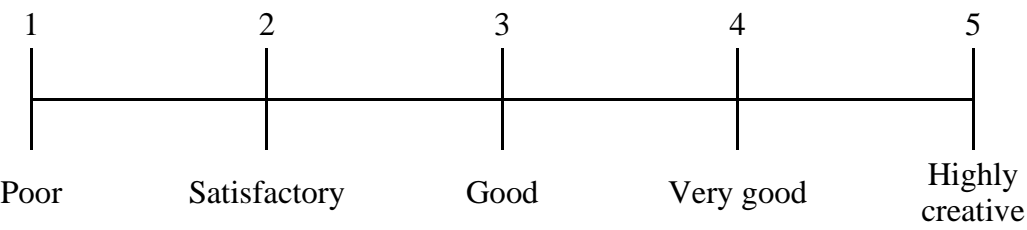

- Engagement - level of motivation, passion for their work, enthusiasm

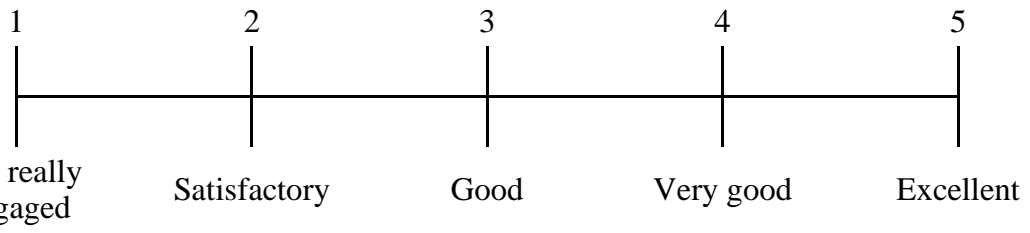

- Understanding - level of understanding of the problem, and application of theory to practice

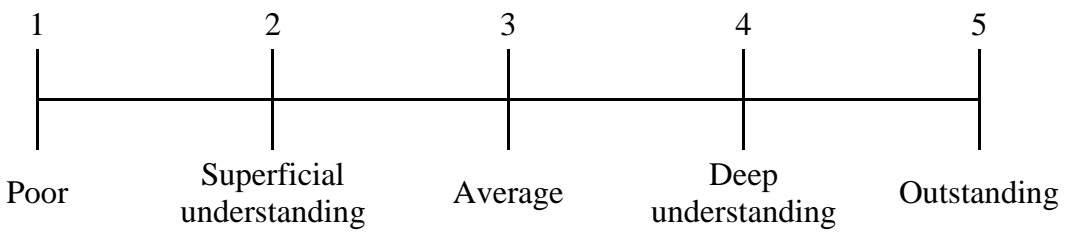

